\title{
Гашенко И.В.
}

\section{СУЩНОСТЬ, ПРИНЦИПЫ И СПЕЦИФИКА НААОГОВОГО РЕГУАИРОВАНИЯ АПК В РОССИИ}

\begin{abstract}
Аннотация. Предметом исследования выступают экономические отночения, возникающие в процессе налогообложения сельскохозяйственных товаропроизводителей. Объектом исследования является налоговое регулирование деятельности прдприятий агропромышиенного комплекса. Развитие агропромышиенного комплекса как системообразующей сферы экономики является одним из приоритетов государственной политики обеспечения продовольственной безопасности и стимулирования развития сельских территорий. Указанные факторы предопределяют необходимость активизации косвенных методов государственного воздействия на развитие отраслей агропромышиенного комплекса, среди которых важную роль играют налоги. Вместе стем, сложившаяся система налогообложения агропромыциенного комплекса не в полной мере обеспечивает выполнение всех возложенных на нее функций, недостаточно учитывает специфику сельского хозяйства. Методологической основой исследования послужили фундаментальные концепции, представленные в трудах отечественных и зарубежных ученых, законодательные и нормативно-правовые акты государственных органов власти, федеральные законы, Указы Президента и Постановления Правительства РФ, материалы научно-практических конференций, затрагивающие вопросы налогообложения сельскохозяйственных товаропроизводителей.В работе использованы абстрактно-логический, монографический, статистико-экономический и другие методы экономических исследований. Новизна исследования заключается в формулировке авторского определения «Налогового регулирования», которое заключается в формировании государством благоприятной среды дяя устойчивого развития предпринимательской деятельности в АПК, посредствам снижения общего уровня налогообложения, установления разнообразных специальных налоговых ıьгот, тем самым, повышая инвестиционную и экономическую привлекательность отрасли. А также выделены и обоснованы основные принципы налогового регулирования в АПК.
\end{abstract}

Ключевые слова: Налогообложение, АПК, Налоговое регулирование, сельхозтоваропроизводитель, налоговые льготы, принципы налогообложения, сельскохозяйственный налог, налоговая нагрузка, намоговая политика, функции налогов.

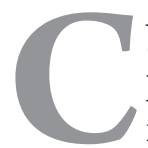

уществующий уровень развития аграрной сферы, низкая инвестиционная привлекательность отрасли, рискованный характер ведения преАпринимательской Аеятельности объективно обуславливают необходимость более взвешенного и системного подхода со стороны федеральных и региональных властей к проведению аграрной политики, позволяющего смягчить отрицательное воздействие рыночного механизма, сформировать конкурентную среду, создать условия Аця Аолгосрочного экономического роста и обеспечить продовольственную безопасность страны.
В этой связи особую актуальность приобретают вопросы совершенствования системы госуАарственного регулирования сельского хозяйства, включающей различные формы и методы госрегулирования, учитывающие современное состояние и специфику аграрной сферы и способствующие повышению конкурентоспособности и устойчивости функционирования современных аграрных формирований и достижению социальной стабильности в отрасли.

В настоящее время существует множество определений такого понятия как «налоговое регулирование», которое в настоящее время носит Аискуссионный характер. Так, А. Н. Аз- 
рилиян в большом экономическом словаре поА налоговым регулированием понимает совокупность мер косвенного воздействия государства на развитие производства путем изменения нормы изъятия в бюАжет за счет понижения или повышения общего уровня налогообложения, разнообразных специальных налоговых мьгот, поощряющих Аеловую активность в отАельных сферах или регионах.

В современном экономическом словаре поА реАакцией Райзберга Б.А. отмечено, что налоговое регулирование - это меры косвенного воздействия на экономику, экономические и социальные процессы путем изменения вида налогов, налоговых ставок, установмения налоговых мьгот, понижения или повышения общего уровня налогообможения, отчискений в бюджет.

По нашему мнению поА налоговым регулированием АПК следует понимать, систему экономического, правового и политического обеспечения государством благоприятной среАы Аля формирования и развития устойчивого развития преАпринимательской деятельности в АПК, посреАствам снижения общего уровня налогообложения, установления разнообразных специальных налоговых мьгот, тем самым, повышая инвестиционную и экономическую привлекательность отрасли.

Мы считаем, что налогообложение аграрных формирований заключается в необходимости государственного регулирования на основе преАоставления иьгот по различным налогам (по налогу на прибыль, земельному налогу, налогу на имущество организаций и т.А.), экспортно-импортной деятельности через квотирование и установление таможенных пошлин на ввозимые продовольственные товары и т.А.

Следует отметить, что налоговое регулирование явмяется весьма мощным инструментом государственного регулирования экономики ююбой страны. Специфика налогового регулирования заключается в том, что Аля преАприятий аграрной сферы в современных условиях первичной является регулирующая функция налогов, а не фискальная. Связано это с тем, что ввиду объективных причин более половины современных аграрных формирований находится в весьма тяжелых финансовых условиях: уровень заработной платы почти в три раза ниже, чем в среАнем по экономике страны; низкий уровень и большая изношенность материально-технической базы, и поэтому отчисление от прибыли, Аоходов физических Аиц, социальных налогов, налога на имущества весьма незначительны.

Таким образом, мы считаем, что на современном этапе развития основной функцией намогов в аграрной сфере является регулирующая, при этом налоговое регулирование Аолжно быть направлено, прежАе всего, на регулирование экспортно-импортной Аеятельности.

Средний уровень налогового бремени в зарубежных странах колеблется от 15 до 40\%. Так, величина налогового бремени в России заметно ниже уровня стран ЕС и Канады, примерно на одном уровне с Японией и США и много выше, чем в бурноразвивающихся экономиках (Индия и Китай), что является отрицательным фактом, учитывая необходимость увеличения темпов экономического развития РФ Ао уровня Индии и Китая (рис. 1).

Налоговое бремя в сельском хозяйстве РФ существенно ниже, чем в среднем по экономике и по итогам 2013 г. оно составлямо около 6,6\%, что объясняется существенными Аьготами Аля предприятий агарной сферы, а именно: $ь$ ьотная ставка НАС, применение специального намогового режима в виде ЕСХН, нулевая ставка по налогу на прибыль и т.А.

Очевидно, что низкое налоговое бремя в целом положительно сказывается на функционировании преАприятий аграрной сферы и Аолжно способствовать привлечению инвестиций в Аанный сектор экономики страны. Но вместе с тем в существующей налоговой системе РФ имеются определенные противоречия, которые тормозят этот процесс. Речь идет о применении специального режима налогообложения Аля семьхозтоваропоризводителей. Аело в том, что одна из основных задач Аанного налогового режима - это повышение 


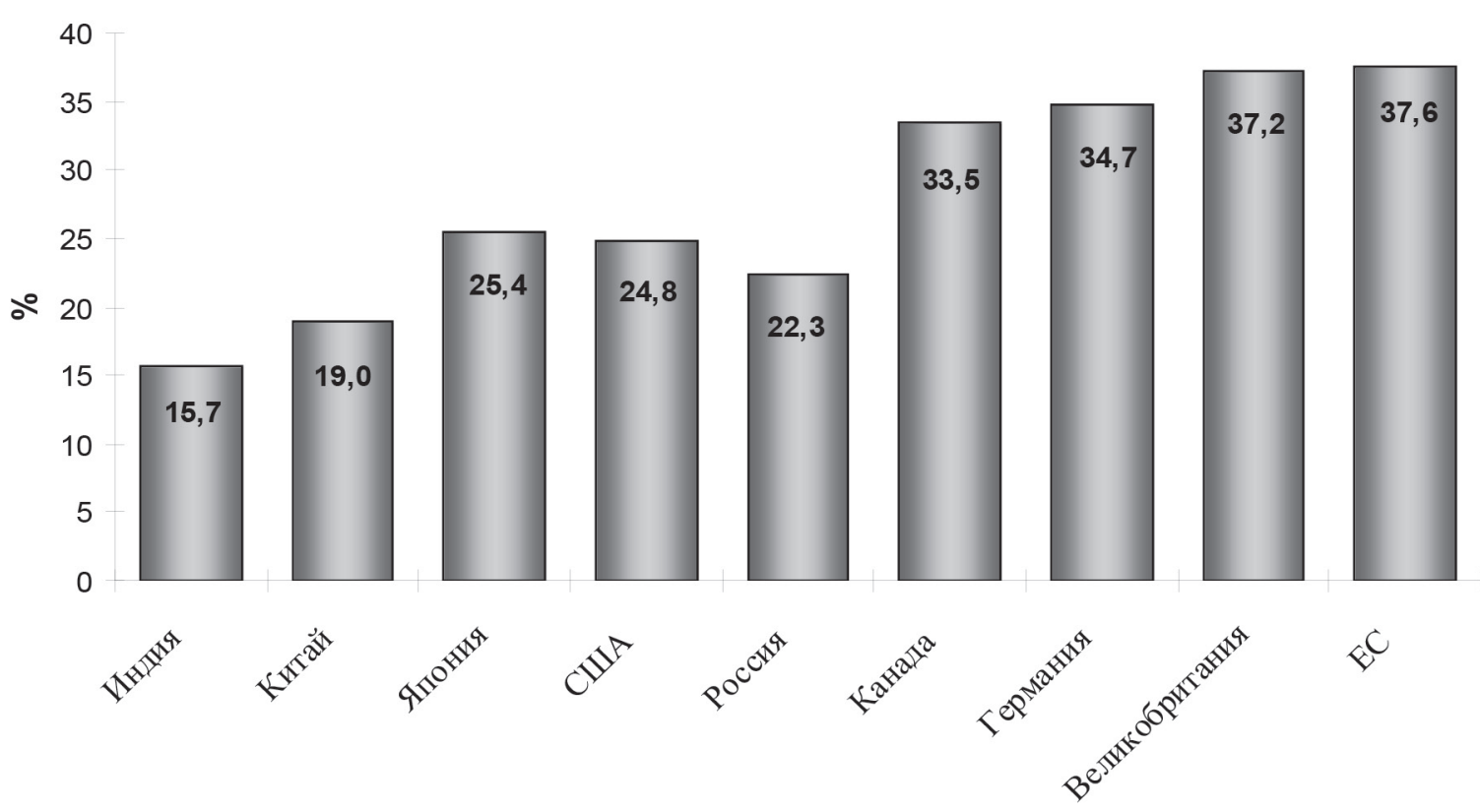

Рис. 1. Уровень налогового бремени в странах мира,\%

инвестиционной привлекатемьности семьского хозяйства.

МежАу тем практика применения ЕСХН показывает, что организациям ики индивиАуальным преАпринимателям, собирающимся привлекать инвестиционные ресурсы в развитие преАприятия, экономически выгоднее оставаться на общем режиме налогообложения.

Таким образом, существующая редакция главы 26.1 НК РФ Аелает экономически не оправданным применение специального налогового режима Аля сельскохозяйственных товаропроизводителей в случае привлечения крупных инвестиционных ресурсов на развитие преАприятия. В этой связи на современном этапе развития семьского хозяйства, когАа отрасль остро нужАается в инвестициях, виАится целесообразным искмючение НАС из перечня неуплачиваемых налогов Аля семьскохозяйственных товаропроизводитекей, применяющих специальный режим налогообложения в виде ЕСХН.

Внешнеэкономическое регумирование через таможенные пошиины и тариф также явцяется составной частью налогового регулирования и имеет свои особенности в аграрном секторе экономики. Несомненно, чем меньше таможенные пошиины, тем дешевле импортное продо- вольствие, а следовательно, бомьше и объемы его потребцения внутри страны. Кроме того, таможенные пошиины являются Аополнительными бюАжетными Аоходами.

Россия не использует в существенных объемах экспортное регулирование в аграрной сфере, что влечет за собой увеличение импорта продовольствия. Так, послеАние несколько мет в РФ ежегодно было импортировано продовоцьственных товаров на сумму более 15 мирА.

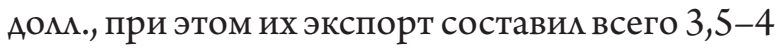
м $\Lambda$ РА. АО $\Lambda$.

По нашему мнению, научно обоснованная система налогообложения семьхозтоваропроизвоАителей - ОАно из необхоАимЫХ Условий успешного реформирования аграрного сектора экономики России. Существующая налоговая система слабо учитывает специфику семьского хозяйства, а в большей степени интегрированных структур, которые в настоящее время явАяются основой семьского хозяйства. Эффективность семьского хозяйства, в отмичие от Аругих отраслей экономики, в значительной степени, как уже говорилось, опреАеляется склаАывающимися природными и климатическими условиями. Они оказывают влияние не только на урожайность семьскохозяйственных культур, 
но и предопределяют уровень затрат хозяйствующего субъекта на осуществление сельскохозяйственной деятельности. Многие исследователи поднимали вопрос о необходимости ввеАения Аифференцированного подхода к налогообложению сельского хозяйства в зависимости от складывающихся природно-климатических условий, что позволит обеспечить равные усмовия хозяйствования. ОАнако до настоящего времени механизмы Аифференциации условий налогообложения не разработаны. Помимо этого многоканальная система налогов ставит сельхозпреАприятия в неравные условия по отношению к налогоплательщикам Аругих отраслей хозяйственного комплекса страны. Пробелы в налоговом законодательстве не Аают возможности крупным (интегрированным) сельхозпреАприятиям получения налоговых мьгот, что тормозит процесс инвестирования.

Таким образом, нам представмяется, что в настоящее время налоговое регулирование АПК Аолжно базироваться на трех основных принципах: регулирующем, стимулирующем и системном (учет единства налоговой системы и взаимодействия различных форм налоговых отношений применительно к конкретному намогопиательщику и особенностей его хозяйственной деятельности).

Регулирующий принцип налогообложения преАпринимательской деятельности в АПК Аолжен преАставлять собой стремление Аостичь баманса интересов межАу различными субъектами в экономике. Использование налогообложения с регулирующей целью позволяет перераспреАелить налоговое бремя между размичными субъектами преАпринимательской деятельности. Наряду с эти это позволяет Аостичь баланса межАу публичными интересами государства и общества, а также частными интересами субъектов в аграрной сфере.

Стимулирующий принцип как цель налогообложения преАпринимательской Аеятельности АПК преАставмяет собой ослабление налогового бремени Аля экономически невыгодных, но социально значимых видов предпринимательской Аеятельности, таких как семьское хозяйство, и усиление налогового бремени Аля экономически выгодных, но социально нейтральных видов преАпринимательской деятельности.

Системный принцип Аолжен основываться на учете единства налоговой системы и взаимоАействия различных форм налоговых отношений применительно к конкретному налогоплательщику и особенностей его хозяйственной Аеятельности.

Специфика финансовых отношений в АПК, в отличие от Аругих отраслей экономики, в значительной степени, определяется естественнобиологическим циклом произвоАства, обусловмивающим кругооборот финансовых ресурсов в соответствии с процессом развития биологических активов, а также сезонность осуществления расходов и получения Аоходов ${ }^{[2]}$. Кроме того, финансовые результаты в АПК находятся в тесной зависимости от скмадывающихся природных и климатических условий. Они оказывают влияние не только на урожайность сельскохозяйственных культур, но и предопределяют Аифференциацию Аоходности вслеАствие неоАнородности затрат хозяйствующих субъектов на осуществление сельскохозяйственной Аеятельности, включая необходимость расхоАов на страхование погодных и иных рисков ${ }^{[3]}$.

Серьезной экономической проблемой АПК явмяется относительно низкий и волатильный уровень рентабельности сельскохозяйственного производства, сокращающий стимулы к инвестированию в развитие и ограничивающий приток капитала ${ }^{[11]}$. Показатель рентабельности продаж и активов в сельском хозяйстве (за искмючением рыбной отрасли) значительно ниже по сравнению со средним значением по экономике (таблица 1).

Вместе с тем, проведенный анализ свидетельствует о более уверенной динамике показателей рентабельности в сельском хозяйстве, чем в Аругих отраслях экономики. Так, за анализируемый период рентабельность продаж сельскохозяйственной продукции увеличилась на 3,7 п.п. (по рыбной отрасли - на 34,8 п.п.), а рентабельность активов - на 2,5 п.п. (по рыбной отрасли - на 31,3 п.п.) при общем сни- 
Таблииа 1. Рентабельность продаж и активов в некоторых отраслях АПК в 2003-2013 г2. (в проиеетах)

\begin{tabular}{|c|c|c|c|c|c|c|c|c|c|c|}
\hline & \multicolumn{2}{|l|}{2003} & \multicolumn{2}{|l|}{2005} & \multicolumn{2}{|l|}{2012} & \multicolumn{2}{|l|}{2013} & \multicolumn{2}{|c|}{2013 к 2003} \\
\hline & $\begin{array}{l}\text { Рента- } \\
\text { бель- } \\
\text { ность } \\
\text { про- } \\
\text { даж }\end{array}$ & $\begin{array}{l}\text { Рента- } \\
\text { бель- } \\
\text { ность } \\
\text { акти- } \\
\text { вов }\end{array}$ & $\begin{array}{l}\text { Рента- } \\
\text { бель- } \\
\text { ность } \\
\text { про- } \\
\text { даж }\end{array}$ & $\begin{array}{l}\text { Рента- } \\
\text { бель- } \\
\text { ность } \\
\text { акти- } \\
\text { вов }\end{array}$ & $\begin{array}{l}\text { Рента- } \\
\text { бель- } \\
\text { ность } \\
\text { про- } \\
\text { даж }\end{array}$ & $\begin{array}{l}\text { Рента- } \\
\text { бель- } \\
\text { ность } \\
\text { акти- } \\
\text { вов }\end{array}$ & $\begin{array}{l}\text { Рента- } \\
\text { бель- } \\
\text { ность } \\
\text { про- } \\
\text { даж }\end{array}$ & $\begin{array}{l}\text { Рента- } \\
\text { бель- } \\
\text { ность } \\
\text { акти- } \\
\text { вов }\end{array}$ & $\begin{array}{l}\text { Рента- } \\
\text { бель- } \\
\text { ность } \\
\text { про- } \\
\text { даж }\end{array}$ & $\begin{array}{l}\text { Рента- } \\
\text { бель- } \\
\text { ность } \\
\text { акти- } \\
\text { вов }\end{array}$ \\
\hline $\begin{array}{l}\text { Всего в } \\
\text { экономике }\end{array}$ & 10,2 & 5,9 & 13,5 & 8,8 & 8,6 & 6,1 & 7,7 & 5,0 & $-5,2$ & $-0,9$ \\
\hline $\begin{array}{l}\text { Сельское } \\
\text { хозяйство, охота } \\
\text { и лесное хозяйство }\end{array}$ & 2,6 & $-0,0$ & 6,7 & 2,8 & 10,7 & 3,5 & 6,3 & 2,5 & $+3,7$ & $+2,5$ \\
\hline $\begin{array}{l}\text { Рыболовство, } \\
\text { рыбоводство }\end{array}$ & $-3,3$ & $-16,2$ & 5,2 & 0,1 & 16,2 & 11,5 & 21,5 & 15,1 & $+34,8$ & $+31,3$ \\
\hline $\begin{array}{l}\text { Обрабатывающие } \\
\text { производства }\end{array}$ & 12,4 & 7,3 & 15,3 & 11,9 & 10,7 & 8,1 & 9,5 & 4,9 & $-2,9$ & $-2,4$ \\
\hline $\begin{array}{l}\text { производство } \\
\text { пищевых продуктов }\end{array}$ & 8,2 & 6,4 & 7,9 & 6,3 & 9,4 & 6,4 & 10,1 & 6,1 & $+1,9$ & $-0,3$ \\
\hline $\begin{array}{l}\text { текстильное и швей- } \\
\text { ное производство }\end{array}$ & 1,4 & $-1,6$ & 2,7 & 1,0 & 6,2 & 3,9 & 7,1 & 3,5 & $+5,7$ & $+5,1$ \\
\hline $\begin{array}{l}\text { производство кожи, } \\
\text { изделий из кожи } \\
\text { и обуви }\end{array}$ & 2,8 & 1,9 & 5,0 & 2,7 & 9,1 & 3,7 & 6,2 & 1,8 & $+3,4$ & $-0,1$ \\
\hline
\end{tabular}

жении рентабельности продаж по экономике на 5,2 п.п., а рентабельности активов - на 0,9 п.п. Кроме того, за период с 2003 по 2013 гг. наблюдается последовательное сокращение отставания рентабельности в сельском хозяйстве, а перерабатывающие отрасли АПК демонстрируют уверенный рост рентабельности продаж.

Объективные сложности аграрной экономики вынужАают большинство стран осуществмять мероприятия госуАарственного регулирования. Семьскохозяйственные налоги не явцяются преАметом регулирования в Соглашении по сельскому хозяйству ВТО, значит, страныучастники не обязаны сокращать налоговые мьготы. В условиях снижения внутренней поААержки сельского хозяйства согласно требованиям ВТО налоги становятся одним из основных инструментов поААержки аграрного сектора ${ }^{[1]}$.

Комплексный подхоА к налоговому регуАированию должен быть ориентирован на учет специфических факторов экономической деятельности в АПК. Мы считаем, что важнейшей особенностью сельскохозяйственного производства, которую Аолжна учитывать налоговая система, явмяется сезонность производства и несовпадение по времени пиков осуществления затрат и получения доходов. ОАним из принципов, сформулированным еще А. Смитом, явмяется «принцип удобства и времени взимания налога Аля налогоплательщика». Исходя из этого принципа, кажАый намог из всей совокупности налогов Аолжен взиматься в такое время и таким способом, которые предоставцяют наибольшие удобства Аля налогоплательщика. Иными словами, при формировании налоговой системы и ввеАении мюбого налога Аолжны быть миквидированы все формальности, акт уплаты налога должен быть максимально упрощен, т.е. налоговый платеж Аолжен приурочиваться ко времени покучения Аохода.

Можно констатировать, что Амя цемей намогового регулирования экономики в России используются те же методы, что и в развитых странах - специальные режимы фискального обложения; пониженные ставки; мьготы в виде полного или частичного освобождения от налога определенных категорий плательщиков, отАельных виАов Аеятельности и Аоходов по ним; перенесение сроков уплаты налогов и сборов на более позАний срок. 


\section{БИБАИОГРАФИЯ}

1. Аелягин М.Г. Некоторые послеАствия присоединения к ВТО Аля сельского хозяйства России / / МежАународная экономика. 2012. № 9. С.17-20; Узун В.Я. Российская политика подАержки сельского хозяйства и необходимость её корректировки после вступления в ВТО // Вопросы экономики. 2012. № 10. С. 132-150.

2. Аобрынин В.А. Государственное регулирование агропромышленного производства. М.: ИНФА РФ, 1998. С.21.

3. Камалян А.К. Налогообложение сельскохозяйственных преАприятий. Воронеж: ФГОУ ВПО ВГАУ. 2005.

4. Оробинская И. В., Казьмин А. Г. Проблемные аспекты применения НАС предприятиями АПК России/ И.В. Оробинская, А. Г. Казьмин // Налоги и финансовое право. - 2014.—№ 12.— C.79-84

5. Оробинская И. В., Казьмин А. Г. Анализ поступления налогов в бюАжеты областей Центрально-Черноземного района / И. В. Оробинская, А. Г. Казьмин // Финансовое право и управление - Москва, № 1, 2012.- Режим доступа к журнаку: http://e-notabene.ru/flc/article_358. html

6. Оробинская И.В., Казьмин А.Г. Таможенное регулирование в России после присоединения к ВТО / И. В. Оробинская, А. Г. Казьмин / Ф Финансы и кредит — Москва, № 48 (576), 2013. $46-55$ c.

7. Оробинская И.В. Методические рекомендации по оптимизации налогообложения горизонтально-интегрированных объединений АПК / И. В. Оробинская / / Налоги и налогообложение-Москва, № 10-2013. - 730-741 с.

8. Оробинская И.В. Основы оптимизации налогообложения сельскохозяйственных товаропроизводителей в России / И.В. Оробинская // Налоги и налогообложение - Москва, № 112013. - 807-817 c.

9. Оробинская И. В. Характеристика налогового потенциала субъектов аграрного сектора России на примере областей ЦЧР/ И. В. Оробинская // Намоги и намогообложение. - 2014. № 6.- С. $579-587$.

10. Составлено автором по: Россия в цифрах. 2014: Крат. стат. сб./Росстат-М., Росстат, 2014. С. 425. Сельское хозяйство, охота и охотничье хозяйство, месоводство в России. 2013: Стат.сб./ Росстат. М., 2013.

11. Тюпакова Н.Н., Бочарова О.Ф. Развитие регулирующей функции налогов в налогообложении сельскохозяйственных товаропроизводителей: Монография. КрасноАар: КубГАУ, 2008. C.10-16.

12. Оробинская И. В. Основы оптимизации налогообложения сельскохозяйственных товаропроизводитемей в России // Налоги и намогообложение. - 2013.- 11. - С. 807-817. DOI: 10.7256/1812-8688.2013.11.9584.

13. Ю.А. Шеховцова Использование налоговых инструментов обеспечения инвестиционной безопасности в Российской Федерации // Налоги и налогообложение. - 2013. - 3.- С. 165-178. DOI: 10.7256/1812-8688.2013.03.1.

14. Оробинская И.В. Налоговые инструменты обеспечения стабимьного развития отраслей АПК // Намоги и намогообложение. - 2014. - 4. - C. 393-400. DOI: 10.7256/18128688.2014.4.12019.

15. Оробинская И.В. Налоговые инструменты обеспечения стабимьного развития отраслей АПК // Намоги и намогообложение. - 2014. - 5. - C. 501-508. DOI: 10.7256/18128688.2014.5.12019. 
16. И.В. Оробинская, А.В. Бурыка Изменение внешней и внутренней политики Российской ФеАерации в отношении сельхозтоваропроизводителей в условиях вступления в ВТО // Налоги и налогообложение. - 2012.-9.- С. 30-33.

17. Н.И. Морозко ААаптивные инструменты налогового планирования в управлении малыми организациями // Намоги и налогообложение. - 2012. - 1. - С. 45-50.

\section{REFERENCES (TRANSLITERATED)}

1. Delyagin M. G. Nekotorye posledstviya prisoedineniya kVTO dlya sel'skogo khozyaistva Rossii // Mezhdunarodnaya ekonomika. 2012. № 9. S.17-20; Uzun V. Ya. Rossiiskaya politika podderzhki sel'skogo khozyaistva i neobkhodimost» ee korrektirovki posle vstupleniya v VTO // Voprosy ekonomiki. 2012. № 10. S. 132-150.

2. Dobrynin V.A. Gosudarstvennoe regulirovanie agropromyshlennogo proizvodstva. M.: INFA RF, 1998. S.21.

3. Kamalyan A. K. Nalogooblozhenie sel'skokhozyaistvennykh predpriyatii. Voronezh: FGOU VPO VGAU. 2005.

4. Orobinskaya I. V., Kaz'min A. G. Problemnye aspekty primeneniya NDS predpriyatiyami APK Rossii/ I. V. Orobinskaya, A. G. Kaz'min / / Nalogi i finansovoe pravo. - 2014.—№ 12.— S.79-84

5. Orobinskaya I. V., Kaz'min A. G. Analiz postupleniya nalogov v byudzhety oblastei Tsentral'noChernozemnogo raiona / I. V. Orobinskaya, A. G. Kaz'min // Finansovoe pravo i upravlenie Moskva, № 1, 2012.—Rezhim dostupa k zhurnalu: http://e-notabene.ru/flc/article_358.html

6. Orobinskaya I. V., Kaz'min A. G. Tamozhennoe regulirovanie v Rossii posle prisoedineniya kVTO / I. V. Orobinskaya, A. G. Kaz’min / Finansy i kredit — Moskva, № 48 (576), 2013. — 46-55 s.

7. Orobinskaya I. V. Metodicheskie rekomendatsii po optimizatsii nalogooblozheniya gorizontal'nointegrirovannykh ob"edinenii APK / I. V. Orobinskaya // Nalogi i nalogooblozhenie-Moskva, № 10-2013.-730-741 s.

8. Orobinskaya I. V. Osnovy optimizatsii nalogooblozheniya sel'skokhozyaistvennykh tovaroproizvoditelei v Rossii / I. V. Orobinskaya // Nalogi i nalogooblozhenie - Moskva, № 112013. - 807-817 s.

9. Orobinskaya I. V. Kharakteristika nalogovogo potentsiala sub"ektov agrarnogo sektora Rossii na primere oblastei TsChR/ I. V. Orobinskaya // Nalogi i nalogooblozhenie.— 2014.— № 6.— S. 579-587.

10. Sostavleno avtorom po: Rossiya v tsifrakh. 2014: Krat. stat. sb./Rosstat-M., Rosstat, 2014. S. 425. Sel'skoe khozyaistvo, okhota i okhotnich'e khozyaistvo, lesovodstvo v Rossii. 2013: Stat.sb./Rosstat. M., 2013.

11. Tyupakova N. N., Bocharova O.F. Razvitie reguliruyushchei funktsii nalogov v nalogooblozhenii sel'skokhozyaistvennykh tovaroproizvoditelei: Monografiya. Krasnodar: KubGAU, 2008. S.10-16.

12. Orobinskaya I. V. Osnovy optimizatsii nalogooblozheniya sel'skokhozyaistvennykh tovaroproizvoditelei v Rossii // Nalogi i nalogooblozhenie. - 2013. - 11. - C. 807-817. DOI: 10.7256/1812-8688.2013.11.9584.

13. Yu.A. Shekhovtsova Ispol'zovanie nalogovykh instrumentov obespecheniya investitsionnoi bezopasnosti v Rossiiskoi Federatsii // Nalogi i nalogooblozhenie. - 2013. - 3. - C. 165-178. DOI: 10.7256/1812-8688.2013.03.1.

14. Orobinskaya I.V. Nalogovye instrumenty obespecheniya stabil'nogo razvitiya otraslei APK // Nalogi i nalogooblozhenie. — 2014. - 4.—C.393-400. DOI: 10.7256/1812-8688.2014.4.12019.

15. Orobinskaya I.V. Nalogovye instrumenty obespecheniya stabil'nogo razvitiya otraslei APK // Nalogi i nalogooblozhenie. - 2014. - 5. - C.501-508. DOI: 10.7256/1812-8688.2014.5.12019. 
16. I. V. Orobinskaya, A. V. Buryka Izmenenie vneshnei i vnutrennei politiki Rossiiskoi Federatsii v otnoshenii sel'khoztovaroproizvoditelei v usloviyakh vstupleniya v VTO // Nalogi i nalogooblozhenie. - 2012.-9.- C. 30-33.

17. N. I. Morozko Adaptivnye instrumenty nalogovogo planirovaniya v upravlenii malymi organizatsiyami // Nalogi i nalogooblozhenie. - 2012.-1.- C. 45-50. 